\title{
Caudal epidural steroid injection: a randomized controlled trial
}

Authors V G Murakibhavi, Aditya Khemka

Institution Department of Orthopaedics, KLE University, Jawaharlal Nehru Medical College, Karnataka, India

\begin{tabular}{l|l}
\hline $\begin{array}{l}\text { Final Class of } \\
\text { evidence-treatment }\end{array}$ & Yes \\
\hline Study design: & \\
\hline RCT & \\
Cohort & \\
Case control & \\
Case series & \\
\hline Methods & \\
\hline Concealed allocation (RCT) & \\
\hline Intention to treat (RCT) & \\
\hline Blinded/independent & \\
evaluation of primary outcome & \\
\hline F/U $\geq 85 \%$ & \\
\hline Adequate sample size & \\
\hline Control for confounding & \\
\hline Overall class of evidence & II \\
\hline & \\
\hline The definiton of the different \\
classes of evidence is available on \\
page 59.
\end{tabular}

\section{ABSTRACT}

Study design: Prospective study.

Study rationale: A recurrent phenomenon, the lifetime prevalence of low back pain has been reported as $54 \%-80 \%$, while annual prevalence ranges from $15 \%-45 \%$ [1]. It is also associated with enormous economic, societal, and health impact [2]. India, being a developing country, has its problem compounded by the occupational compulsions in parts of the rural areas [3].

For some interventional therapies, like epidural steroid injections, utilization rates have increased dramatically [4-9]. They have become one of the most commonly performed interventions in the United States for low back pain with radiculopathy [10].

Clinical question: Multiple systematic reviews [11], a meta-analysis [12], several guidelines [13], health technology assessments by insurers, and local medical review policies and coverage decisions have been published. However, controversy continues regarding the effectiveness of epidural steroid injections. In addition three types of epidurals, namely interlaminar, transforaminal, and caudal, with variable results complicate the picture for practice of interventional pain management. The underlying mechanism of action of epidurally administered steroid and local anesthetic injections is still not well understood and compounds the problem [14].

Objective: To evaluate and update the effects of caudal epidural injection in the management of chronic low back pain and sciatica.

UWMC IRB-approved.

Supported by grants from the NIH/NIAMS 5K23AR48979 and 5P60-AR48093 and supported in part by the Spine End-Results Research Fund at the University of Washington Medical Center through a gift from Synthes Spine (Paoli, PA). 


\section{METHODS}

Study design: This prospective study was approved by our institution's Scientific Research Board and was conducted in accordance with the World Medical Association Declaration of Helsinki. Patients were randomly allocated to groups (conservative treatment, group $\mathrm{A}$; intervention, group, B) by computerassisted software.

- All patients were informed of the study and consented to participate. Between June 2009 and June 2010, a group of 100 patients suffering from low back pain with unilateral or bilateral sciatica for at least 3 months and who were not responding to rest and analgesics were offered enrollment in the study (Fig 1).

- All patients had undergone magnetic resonance imaging (MRI) scans before assessment for eligibility, confirming the existence of lumbar disc disease (disc degeneration or herniation). Patients were randomly allocated to groups (conservative treatment, group A; intervention, group B) by computerassisted software (Table $\mathbf{1}$ ).

- The patients in group A received conservative treatment measures which included medication, such as tizanidine (6-12 $\mathrm{mg} / 24$ hours) for muscle spasms, diclofenac (50-100 mg) each day as needed for pain, and amitriptyline (10-50 mg at night), bilateral skin traction, and physiotherapy which included transcutaneous electrical nerve stimulation, shortwave diathermy, and back extension exercises. The patients allocated to group B underwent a caudal epidural steroid injection with $20 \mathrm{~mL}$ of normal saline, $2 \mathrm{~mL}$ of $2 \%$ preservative-free Xylocaine ${ }^{\circledR}$, and $2 \mathrm{~mL}(40 \mathrm{mg} / \mathrm{ml})$ of triamcinelone acetate [15, 16]. All injections were performed by the first author (VGM). Neurological status and Straight Leg Raise test responses were assessed before and after injection.

Methods: For the procedure, the patient was placed in a prone/lateral position on the operating table. Following skin preparation, the sacral hiatus was identified and both the skin overlying the sacral hiatus and the underlying ligaments were infiltrated with $2-3 \mathrm{~mL}$ of $2 \%$ preservative-free Xylocaine ${ }^{\circledR}$ without epinephrine. At all steps vital signs includ- ing respiratory rate, pulse rate, and blood pressure were monitored by an anesthetist. A 22-gauge spinal needle was placed between the sacral cornu at about $45^{\circ}$, with the bevel of the spinal needle facing ventrally until contact with the sacrum was made in the "sacral triangle." The needle was then redirected more cephalad, horizontal, and parallel to the table, advancing it into the sacral canal through the sacrococcygeal ligament and into the epidural space. This was followed by an aspiration test, then the "hoosh" test (injection of air into the caudal epidural space with simultaneous auscultation over the thoracolumbar spine) [17], hanging drop test (a drop of injected saline staying at the Luer-lock of the needle and not getting sucked in or expressed together with other fluid), and a C-arm were used to confirm the presence of the needle within the canal.

Outcomes: Following screening and enrollment (visit one), all patients were physically examined. The visual analogue scale (VAS) was obtained for low back pain, also the Oswestry disability index (ODI) questionnaire (ODI) $[15,16]$, the Beck depression inventory questionnaire, and the numerical pain intensity (NPI) questionnaire as part of health-related quality of life assessment tools. Imaging included lumbar spine x-rays, MRI of the lumbosacral spine, routine complete blood count, and urine analysis.

Clinical evaluations were performed immediately after injection for patients in group B at 3 weeks (visit two), at 3 months (visit three), and at 6 months (visit four) for both groups. The VAS, ODI score, and the Straight Leg Raise Test (SLRT) (positive $<60^{\circ}$ ) were used to differentiate patients whose symptoms improved from those who remained symptomatic. At reevaluation if a patient had complete or no pain, then no further injection therapy was conducted. If a patient had partial-pain relief in 1 week from the time of the injection with a VAS score reduction not more than $20 \%$, a repeated injection was done on an average 2-3 weeks after the first injection. For patients being treated conservatively, the therapy was continued up to 3 months after which if there was no pain relief then they were allowed to opt for the intervention. These patients were not included in the study. 
Analysis: On the basis of our literature search, we determined that a sample size of 50 participants in each group was sufficient for this study using a desired power of 0.8 and error of 0.05 [15]. The primary analysis of power was the pain score. Statistical analysis was performed using the Student paired $t$ test when appropriate with $P<.05$ required to reject the null hypothesis. The SPSS statistical software (version 17) was used. Also the total amount incurred from treatment of both groups was calculated and analyzed.

Fig 1 Patient sampling and selection.

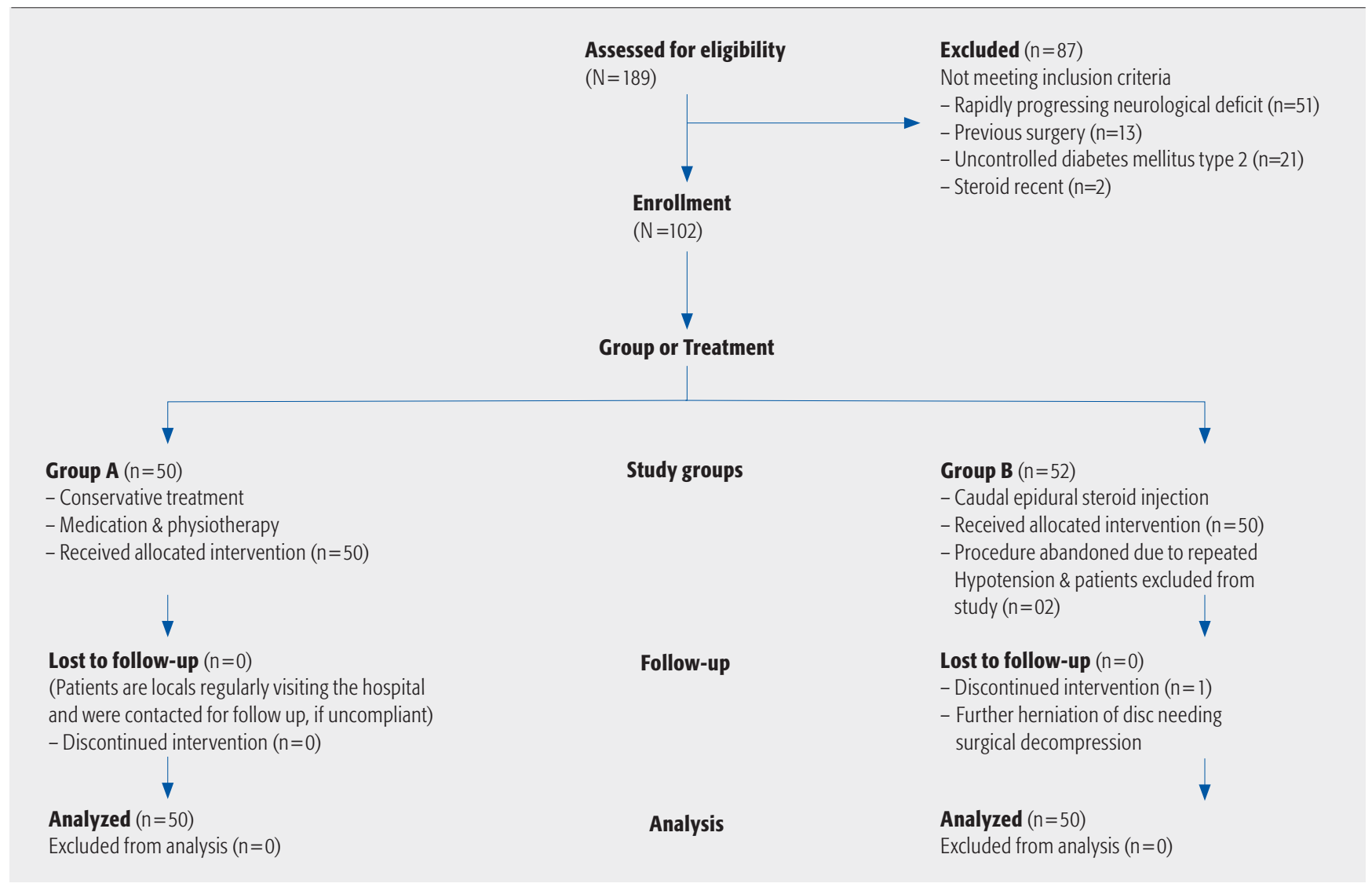

Table 1 Inclusion and exclusion criteria.

\begin{tabular}{ll}
\hline Inclusion criteria & Exclusion criteria \\
\hline $\begin{array}{l}\text { Chronic low back pain with unilateral or } \\
\text { bilateral sciatica }>3 \text { months }\end{array}$ & Cases with history of surgery \\
\hline Refractory to analgesics & Cases with severe motor weakness, rapidly progressing neurological deficits, cauda equina syndrome, neurogenic claudication \\
\hline Patients 18 years or older & Local infection at the site of injection \\
\hline & Use of steroids 3 week or less before the study \\
\hline & Allergy to steroids, bleeding diatheses, pregnancy \\
\hline & Uncontrolled hypertension, uncontrolled diabetes mellitus, and/or were not included in the study \\
\hline
\end{tabular}




\section{RESULTS}

- Our study screened 187 patients for inclusion (Fig 1). A total of 100 patients were enrolled and completed the study. Demographic data of these patients is presented in Table 2.

- Occupation was a major contributory factor to the chronic low back pain with sciatica. Occupations like of farming and heavy weight-lifting by laborers were deemed a major cause for disc prolapse (Fig 2).

- Pain relief was the primary index for evaluating the outcome of the study. Three weeks was considered short term and 24 weeks as long term for the purpose of our evaluation. We found that the intervention group had a large number of patients who reported complete pain relief even at the end of the 6-month evaluation period (Table $\mathbf{3}$ ).

- Oswestry disability index scores were significantly improved within the intervention group. The patients' mean scores kept decreasing (representing improvement of symptoms) at all follow-up reevaluations. The mean ODI score was statistically significantly lower

Fig 2 Occupation distribution in the patient population.

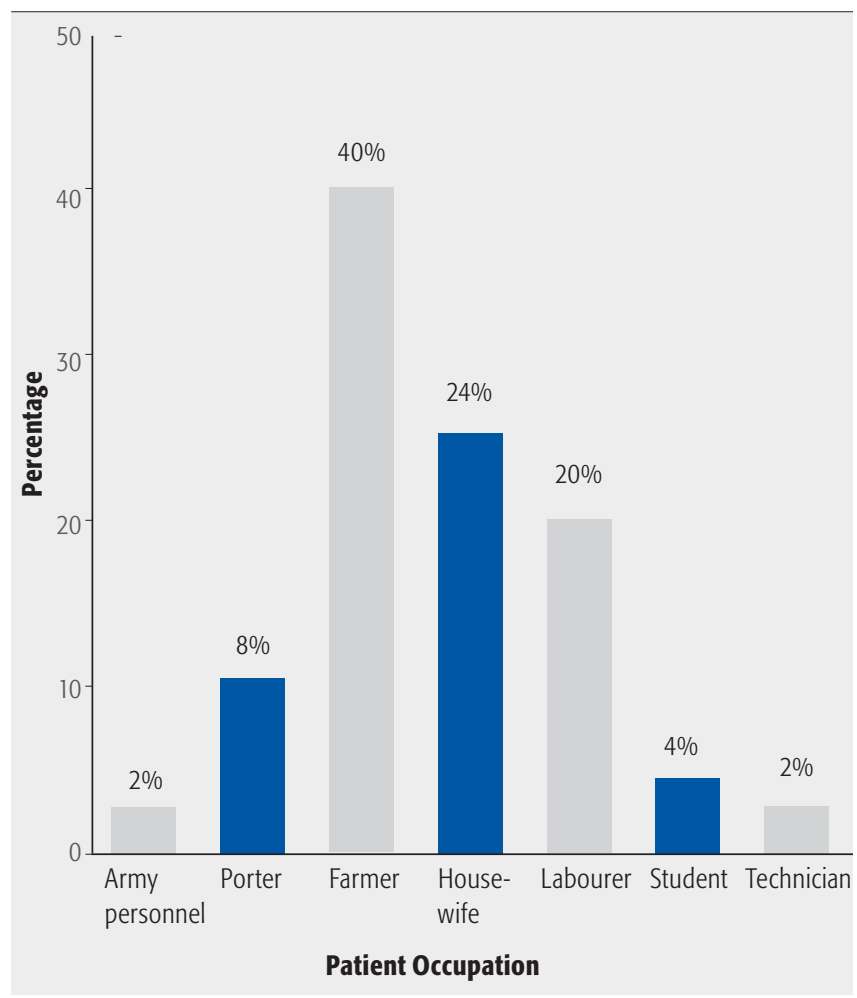

Table 2 Demographic and clinical data of patients.

\begin{tabular}{|c|c|}
\hline Age, $y^{*}$ & $44.64(12.65)$ \\
\hline \multicolumn{2}{|l|}{ Gender } \\
\hline Men & 66 \\
\hline Women & 34 \\
\hline Duration of symptoms before injection, mo* & $21.36(14.22)$ \\
\hline \multicolumn{2}{|l|}{ Signs and symptoms (visit 1$)^{\dagger}$} \\
\hline Low back pain (only up to gluteal region) & $14(14 \%)$ \\
\hline Left sciatica & $38(38 \%)$ \\
\hline Right sciatica & $20(20 \%)$ \\
\hline Bilateral & $28(28 \%)$ \\
\hline Stiffness & $56(56 \%)$ \\
\hline Sensory parasthesia & $90(90 \%)$ \\
\hline Spinal tenderness & $80(80 \%)$ \\
\hline Paraspinal muscle spasm & $88(88 \%)$ \\
\hline \multicolumn{2}{|l|}{ Previous treatment ${ }^{\dagger}$} \\
\hline Rest/analgesics & $98(98 \%)$ \\
\hline Traction & $78(78 \%)$ \\
\hline Orthosis (lumbosacral belt) & $76(76 \%)$ \\
\hline Physiotherapy & $76(76 \%)$ \\
\hline Epidural injections & $09(18 \%)$ \\
\hline \multicolumn{2}{|l|}{ - No. (mean) $)_{-1}^{-1}$} \\
\hline \multicolumn{2}{|l|}{ - Interval (mean) $)_{-1} 1$ y } \\
\hline \multicolumn{2}{|l|}{ Plain -x-ay findings ${ }^{*}$} \\
\hline Muscle spasm & $58(58 \%)$ \\
\hline Reduced disc space & $24(24 \%)$ \\
\hline No abnormality & $18(18 \%)$ \\
\hline \multicolumn{2}{|l|}{ Magnetic resonance imaging findings ₹ } \\
\hline Disc degeneration & $60(60 \%)$ \\
\hline Disc bulge & $26(26 \%)$ \\
\hline Disc herniation (protrusion) & $14(14 \%)$ \\
\hline
\end{tabular}

* The values are given as the mean with the standard deviation within parentheses.

† Values are given as raw numbers with the percentages within parentheses.

‡ Values are given as raw numbers.

Table 3 Pain relief evaluation.*

\begin{tabular}{lllll}
\hline & \multicolumn{2}{c}{ Short term } & \multicolumn{2}{c}{ Long term } \\
\cline { 2 - 5 } & Group A & Group B & Group A & Group B \\
\hline Complete relief & $16(32 \%)$ & $46(92 \%)$ & $12(24 \%)$ & $43(86 \%)$ \\
\hline Partial relief & $20(40 \%)$ & $3(6 \%)$ & $24(48 \%)$ & $6(12 \%)$ \\
\hline No relief & $14(28 \%)$ & $1(2 \%)$ & $14(28 \%)$ & $1(2 \%)$ \\
\hline
\end{tabular}

* Values are raw numbers. 
compared with the score before injection. The observed decreases of the mean ODI scores (a) between visit 1 and 2, and (b) between visit 1 and 4, were statistically significant (Table 4).

- Beck depression inventory scores and function evaluated by VAS and NPI score improved within the group (Table 4). The pain relief was documented in group A as well but was not found to be statistically significant.

- Starting at visit 2 and continuing until visit 4, the SLRT kept improving in the intervention group. This statistically significant improvement was noted in the SLRT. Also a Kaplan-Meier analysis showed the mean time necessary for this improvement was lower in group B compared with group A. Patients enrolled in the study were much more likely to have pain relief and a negative SLRT sign following a caudal epidural injection.

- No patient reported any immediate or late complication(s) following the caudal epidural steroid injection which have been documented in the literature. Twenty patients reported experiencing transient bilateral lower extremity numbness immediately after the injection.

- Hypotension encountered during the procedure was seen in $24 \%$ of the patients and was considered a complication of the needle placement in the caudal region leading to a vaso-vagal response. It was managed promptly by stopping the procedure and monitoring the patients' vital signs, following which a second attempt was made. If the hypotension repeated, then the procedure was abandoned.
- Complications seen with the procedure included technical difficulties associated with passing the sacrococcygeal ligament, also dural puncture and headaches.

- The number of patients requiring repeated injections totaled six, and five of them recovered completely; while one patient had no pain relief. A second MRI showed deterioration of the herniation, following which surgical decompression was performed (Table 5).

- We found no lower limb dysfunction in terms of loss of sensation and/or reduced motor power, or bladder and bowel dysfunction(s).

- Follow-up at 12 months after injection identified sustained positive long-term effects of the injection, with 36 patients $(72 \%)$ reporting complete pain relief.

- The cost incurred from treatment of the patient in the conservative group was significantly higher compared with the amount spent on the patient in the intervention group.

- Occupation has a major role in the incidence of low back pain.

- There was a statistically significant change in the ODI, Beck depression inventory, and NPIS as well as VAS between the first and last visits after administration of epidural steroid.

- Hypotension was a major complication of the procedure in our experience.

Table 4 Visual analogue score (VAS), Oswestry disability index (ODI), Beck depression inventory questionnaire (BDI), and numerical pain intensity scores.

\begin{tabular}{|c|c|c|c|c|c|c|}
\hline & \multicolumn{2}{|c|}{ Mean score } & \multicolumn{2}{|c|}{ Standard deviation } & \multicolumn{2}{|c|}{$\begin{array}{l}\text { Significance within group } 95 \% \\
\text { confidence interval } P \text { value }\end{array}$} \\
\hline & Group A & Group B & Group A & Group B & Group A & Group B \\
\hline VAS before injection & 8.12 & 8.06 & \pm 1.2 & \pm 1 & & \\
\hline VAS after intervention & & 2.02 & & \pm 1.6 & & $<.01$ \\
\hline VAS follow up & 6.08 & 2.69 & \pm 0.5 & \pm 0.8 & $>.05$ & $<.01$ \\
\hline ODI before ntervention & 35.87 & 36.04 & \pm 2.6 & \pm 2 & & \\
\hline ODI after intervention & & 11.94 & & \pm 5.6 & & $<.01$ \\
\hline ODI follow up & 24.87 & 12.28 & \pm 1.5 & \pm 2.6 & $>.05$ & $<.01$ \\
\hline BDI before intervention & 18.93 & 18.04 & \pm 3.2 & \pm 2.7 & & \\
\hline BDI follow up & 13.26 & 8.59 & \pm 1.7 & \pm 2.2 & $>.05$ & $<.01$ \\
\hline NPI before intervention & 8.44 & 8.26 & \pm 1.2 & \pm 0.8 & & \\
\hline NPI follow up & 5.58 & 3.34 & \pm 1.6 & \pm 1 & $>.05$ & $<.01$ \\
\hline
\end{tabular}


Table 5 Complications in patients during the procedure.*

\begin{tabular}{ll}
\hline Complication & No. (\%) of patients \\
\hline $\begin{array}{l}\text { Attempts required for steroid placement } \\
\text { One }\end{array}$ & $35(70)$ \\
Two & $11(22)$ \\
Three & $4(8)$ \\
\hline Difficulty in approach & $11(22)$ \\
\hline Dural puncture (cerebrospinal fluid tap) & $($ none) \\
\hline Headache & $9(18)$ \\
\hline Hypotension (recorded during procedure) & $12(24)$ \\
\hline Bleeding (at the time of injection) & $2(4)$ \\
\hline Repeat injections & $6(12)$ \\
No. required (mean) & 1 \\
\hline Surgery required & 1 \\
\hline
\end{tabular}

- Improvement following the second repeated injection in most patients and the small number requiring a second injection helped in documenting the efficacy of the procedure.

- The intervention proved to be a much more cost-effective procedure for the patients.

\section{DISCUSSION}

\section{Strengths}

- There is a high morbidity associated with chronic low back pain and its associated management [18]. The etiology of chronic low back pain remains unclear [19, 20]. Disc degeneration, herniation, or by an inflammatory reaction could be responsible for lower backache [17]. In 1901, Sicard introduced the injection of cocaine through the caudal route into the epidural space and ever since caudal epidural steroid injections are commonly used when dealing with chronic low back and/or radicular pain [19]. This approach to the epidural space is the earliest known technique for epidural steroid injection or blocks [21]. However, it did not gain universal recognition until 1925 when Viner popularized its use [21]. The first published report from Evans reported good results of caudal epidural injections containing saline in patients with low back pain [19]. The results were attributed to the physical displacement of the nerves and to lysis of neuronal adhesions provided by the injected saline [18].

- Since then numerous studies tried to evaluate the efficacy of caudal epidural steroid injections in patients with chronic low back pain and sciatica. Extensive literature research revealed only a few randomized, double-blind prospective studies assessing the efficacy of this injection technique [19].

- Dansfield et al [20] evaluated caudal epidural injection and root blocks, but concluded that both treatments were effective and had no significant differences. Singh and Manchikanti [19] evaluated caudal epidural injections with limited success. Bush and Hillier [22] evaluated the injections containing steroid and saline and concluded that in the short term they were effective but the long-term potency was variable. Cuckler et al [18] did a similar study with variable results but favored steroid placement.

- We assessed the efficacy of caudal epidural steroid injections containing a preparation of local anesthetic and steroid in a group of patients with chronic low back pain and sciatica.

- Our results showed that 50 patients from the group responded well to the first injection itself. Recovery from symptoms was evaluated by ODI score primarily and was steadily observed from the first week following the injection. The main therapeutic result of the injection appeared during the first week itself, when an immediate decrease in the mean ODI score of the patients was noticed (Table 5).

- Our results support the existence of both short-term and long-term (up to 6 months) relief from symptoms for the group.

- All our patients had MRI confirmation for the pathology [17]. Although the efficacy of caudal epidural steroid injections in the treatment of low back pain and sciatica has been demonstrated, the purported mechanisms of such benefits continue to lack scientific validation [23]. It is hypothesized that corticosteroids exert their antiinflammatory actions either by inhibiting the synthesis or release of inflammatory substances [23]. Membrane stabilization, inhibition of neural peptide synthesis or action of phospholipase A2 activity, and prolonged suppression of ongoing neuronal discharge are also possible effects of corticosteroids [19]. The administration of any saline solutions may dilute locally accumulated chemical irritants [17].

- The advantages of our study are the large number of patients enrolled, use of validated questionnaires as outcome measures instead of subjective criteria as well as the detailed statistical analysis. 
- The chance of puncturing the dura appears low using the caudal method. The lumbar method carries a risk of trauma to the nerve root during needle placement and also includes the risk of paraplegia if steroid is injected into a radicular artery that supplies the anterior spinal artery [24]. Furthermore, disc infiltration can be a complication of the lumbar access route as well.

\section{Limitations}

- Our study also has various limitations. Caudal epidural injections were performed without image intensifier contrast injection performing an epidurogram, which some consider the gold standard for accurate needle placement. We used several substitute techniques to confirm proper needle placement without epidurogram, such as the "whoosh" test and aspiration as well as palpating the right landmarks [26, 27]. Stitz and Sommer [26] report successful infiltration in $92 \%$ of cases, as long as readily palpable anatomical landmarks are properly recognized.

- Our article could have been improved with a control group using local anesthetic only. We also decided against a placebo-control group because of the pain severity of our patients and ethical concerns about withholding care. Hence a nonintervention control group was chosen for comparison.

\section{Clinical relevance and impact}

Caudal epidural steroid injection offers a relatively simple, rapid, and easily performed day-care procedure that can offer significant pain relief. It may even be considered as an alternative to operative procedures in patients not responding well to conservative treatment, of high operative risk, or when they refuse surgery. Following injection, patients are discharged; thus avoiding long periods of hospitalization and bed rest. The combination of local anesthetics, steroids, and saline could be an additional benefit leading to greater and faster relief during the first week, with improvement noted even 6 months later. Certainly more studies would be helpful to better understand the potential action of steroids when treating patients with low back pain and sciatica with caudal epidural injections.

\section{CONCLUSION}

Caudal epidural steroid injections seem to be effective when treating patients with low back pain and sciatica. They are easy to perform, less technically demanding, and with low complications compared with conservative treatment. Caudal epidural injections may offer an interesting alternative approach to managing low back pain and sciatica.

\section{REFERENCES}

1. Lawrence RC, Helmick CG, Arnett FC, et al (1998) Estimates of the prevalence of arthritis and selected musculoskeletal disorders in the United States. Arthritis Rheum; 41(5):778-799.

2. Saastamoinen $\mathbf{P}$, Leino-Arjas $\mathbf{P}$, Laaksonen $\mathbf{M}$, et al (2005) Socio-economic differences in the prevalence of acute, chronic and disabling chronic pain among ageing employees. Pain; 114(3):364-371.

3. Sharma SC, Singh R, Sharma $A K$, et al (2003) Incidence of low back pain in workage adults in rural North India. Indian J Med Sci; 57(4):145-147.

4. Desmoulin GT, Yasin NI, Chen DW (2007) Initial results using Khan Kinetic Treatment ${ }^{\mathrm{TM}}$ as a low back pain treatment option. J Musculoskel Pain; 15(3):91-102.

5. Peng B, Wu W, Li Z, et al (2007) Chemical radiculitis. Pain; 127(1-2):11-16.

6. Mulleman D, Mammou S, Griffoul I, et al (2006) Pathophysiology of disc-related sciatica. I-Evidence supporting a chemical component. Joint Bone Spine; 73:151-158.

7. Macario A, Pergolizzi JV (2003) Systematic literature review of spinal decompression via motorized traction for chronic discogenic low back pain. Spine; 6(3):171-178.

8. Slipman CW, Shin CH, Patel RK, et al (2002) Etiologies of failed back surgery syndrome. Pain Med; 3(3):200-217.

9. Friedly J, Chan L, Deyo R (2007) Increases in lumbosacral injections in the Medicare population: 1994 to 2001. Spine; 32(16):1754-1760.

10. Manchikanti L (2006) Medicare in interventional pain management: A critical analysis. Pain Physician; 9(3):171-197.

11. Abdi S, Datta S, Lucas LF (2005) Role of epidural steroids in the management of chronic spinal pain: a systematic review of effectiveness and complications. Pain Physician; 8(1):127-143.

12. Watts RW, Silagy CA (1995) A meta-analysis on the efficacy of epidural corticosteroids in the treatment of sciatica. Anaesth Intensive Care; 23(5):564-569.

13. Boswell MV, Shah RV, Everett CR, et al (2005) Interventional techniques in the management of chronic spinal pain: evidence-based practice guidelines. Pain Physician; 8(1):1-47.

14. Byröd G, Otani K, Brisby $\mathbf{H}$, et al (2000) Methylprednisolone reduces the early vascular permeability increase in spinal nerve roots induced by epidural nucleus pulposus application. J Orthop Res; 18(6):983-987.

15. Ackerman WE III, Ahmad M (2007) The efficacy of lumbar epidural steroid injections in patients with lumbar disc herniations. Anesthesia Analog; 104(5):1217-1222. 
16. Abdi S, Datta S, Trescot A M, et al (2007) Epidural steroids in the management of chronic spinal pain: a systematic review. Pain Physician; 10(1):185-212.

17. Boswell MV, Hansen HC, Trescot AM, et al (2003) Epidural steroids in the management of chronic spinal pain and radiculopathy. Pain Physician; 6(3):319-334.

18. Cuckler JM, Bernini PA, Wiesel SW, et al (1985) The use of epidural steroids in the treatment of lumbar radicular pain. A prospective, randomized, double-blind study. J Bone Joint Surg Am; 67(1):63-66.

19. Singh V, Manchikanti L (2002) Role of caudal epidural injections in the management of chronic low back pain. Pain Physician; 5(2):133-148.

20. Dashfield AK, Taylor MB, Cleaver JS, et al (2005) Comparison of caudal steroid epidural with targeted steroid placement during spinal endoscopy for chronic sciatica: a prospective, randomized, double-blind trial. Br J Anaesth; 94(4):514-519.

21. Ogoke BA (2000) Caudal epidural steroid injections. Pain Physician; 3(3):305-312.

22. Bush K, Hillier S (1991) A controlled study of caudal epidural injections of triamcinelone plus procaine for the management of intractable sciatica. Spine; 16(5):572-575.

23. Boscainos PJ, Sapkas G, Stilianessi E, et al (2003) Greek versions of the Oswestry and Roland-Morris Disability Questionnaires. Clin Orthop Relat Res; 411:40-53.

24. Quintero N, Laffont I, Bouhmidi L, et al (2006) [Transforaminal epidural steroid injection and paraplegia: case report and bibliographic review]. Ann Readapt Med Phys; 49(5):242-247. French.

25. Tsui BC, Tarkkila P, Gupta S, et al (1999) Confirmation of caudal needle placement using nerve stimulation. Anesthesiology; 91(2):374378.

26. Stitz MY, Sommer HM (1999) Accuracy of blind versus fluoroscopically guided caudal epidural injection. Spine; 24(13):1371-1376.

27. Eastwood D, Williams C, Buchan I (1998) Caudal epidurals: the whoosh test. Anaesthesia; 53(3):305-307.

\section{EDITORIAL PERSPECTIVE}

The reviewers welcomed a prospectively randomized controlled trial on this controversial subject using well-selected outcomes investigations. Interestingly this study pooled a wide variety of manifestations of low back disorders with little differentiation of care for either subset of disc degeneration, herniation, or simple muscle spasms. Murakibhavi and Khemka's study adds an interesting perspective with a simple form yet underreported technique for epidural steroid injections presented. Our reviewers commented that the efficacy and efficiency of lumbar spinal epidural steroids in the treatment of low back pain and radiculopathy remains controversial. In larger formal studies, such as the US Food and Drug Administration study comparing $X$ Stop and epidural steroid injections, lumbar epidural steroid injections have failed to demonstrate significant improvements beyond some short-term benefits (www.fda.gov/ohrms/DOCKETS/dockets/06m0014/06m-0014aav0001-03-SSED-voll.pdf). The difference of outcomes of this study and other trials cannot be readily explained with technique or patient selection. Cultural differences and varying healthcare expectations remain significant confounding factors.

The reviewers also suggested longer follow up in this study beyond 6 months would be highly desirable.

An actual cost comparison of the caudal epidural technique to the discussed nonoperative strategies would have been interesting. Discussion of cost in healthcare delivery is a complex multifactorial undertaking with individual, health-system and societal costs to be considered, yet important as interventional and nonoperative care options are compared. Similarly, return to work as an outcome parameter is a complex undertaking with multiple surrounding issues influencing this variable.

There were several opportunities missed for more detailed assessment of the nature of the radiculopathy experienced by patients beyond a description of positive straight leg raise pain. Considerations such as numbness, weakness, functional status are important covariables in the management of radiculopathy and are not identified in this study, but are of relevance in the outcomes of patients with lumbar disc pathology [1].

The reviewers also identified that in absence of direct comparisons with other techniques of epidural injections, comments on complications or outcomes are not appropriate.

In designing future studies, this study could seemingly incite a comparison of caudal blocks to interlaminar and transforaminal steroid injections to get a better understanding on the effects of this treatment modality. This study is definitely an interesting option for interventional management of simple low back pain due to a variety of causes, and based on the results published will hopefully inspire further investigation.

1. Weinstein JN, Tosteson TD, Lurie JD, et al (2006) Surgical vs nonoperative treatment for lumbar disc herniation: the Spine Patient Outcomes Research Trial (SPORT): a randomized trial. JAMA; 296:2441-2450. 